\title{
Low-dose X-ray imaging for paediatric trauma comes of age
}

\author{
Arjan B. Van $\mathrm{As}^{\mathrm{a}^{*}}$, Ebrahim Banderker ${ }^{\mathrm{b}}$ \\ ${ }^{\text {a }}$ Division of Paediatric Surgery, Faculty of Health Sciences, University of Cape Town, Cape Town, South Africa \\ ${ }^{\mathrm{b}}$ Division of Radiology, Faculty of Health Sciences, University of Cape Town, Cape Town, South Africa
}

Received 26 February 2019; Accepted 9 April 2019; Published online 30 May 2019

$\mathrm{X}$-ray imaging is the most frequently employed diagnostic imaging modality in clinical medicine. The damaging effects of ionising radiation, on which X-ray imaging relies, on human tissue have been long known. The heightened risks of ionising radiation to young children in general paediatric practice are well established. Particularly vulnerable tissues include the rapidly dividing cells of the gonads, gut, lung, thyroid and breast (Ron, 2002). The increased oncogenic potential of ionising radiation in children poses significant challenges for modern paediatric practice (Willis \& Slovis, 2004).

In this context, the Lodox low-dose full-body X-ray imaging system was installed at the trauma unit of the Red Cross War Memorial Children's Hospital in Cape Town, South Africa, in 2004 (Douglas et al., 2010). The first diagnostic Lodox imaging system was installed at the trauma unit of Groote Schuur Hospital in Cape Town in 1996 and proved revolutionary in its clinical application for the management of trauma patients, and most notably in those presenting with polytrauma (Beningfield et al., 2003). A second Lodox system was installed elsewhere in South Africa soon thereafter, and the advantages of this new technology as compared with conventional X-ray imaging techniques were highlighted in the international medical literature (Boffard et al., 2006). The first Lodox System installation outside South Africa was in Baltimore, Maryland, United States (Mulligan \& Flye, 2006).

Polytrauma patients routinely undergo multiple radiographic examinations - skull, cervical spine, chest and pelvis. After positioning of the patient on the trolley of the imaging device, the Lodox system can deliver a full body scan within 13 seconds. The trauma doctor can immediately focus on the anatomical areas of concern and also digitally manipulate the image for better injury detection. The use of Lodox in a polytrauma patient reportedly reduced the imaging time using conventional techniques from an average 48 minutes to 6 minutes, thereby adding an additional 42 minutes to the so called "golden hour" of early trauma management, which, when lost, adversely affects patient outcomes (Zuidgeest et al., 2013). Besides the gain in diagnostic time, the positioning of the Lodox imaging system in the treatment area in the trauma unit, eliminates the time and complications associated with transfer to the radiology suite.

After the successful introduction of the Lodox imaging device in the field of trauma care, its usefulness was promptly extended to other fields such as forensic pathology where it is well suited to achieve a detailed survey of the entire body to detect fractures and foreign bodies such as bullets or shrapnel (Knobel, Flash, \& Bowie, 2006). The utilization of the Lodox system in paediatric practice, however, arguably yields the most benefits. Whereas the "golden hour" has been described in the management of adult trauma, for children it is of even greater importance to keep the diagnostic duration as brief as possible. Paediatric patients have less physiological reserve in the event of blood loss and consequent decreased supply of cerebral oxygen.

Infants and traumatized children are unable to describe their pain and localize symptoms as precisely as older children and adults do. In addition, the majority of children presenting with severe trauma also suffer traumatic brain injury and are obtunded (Maas et al., 2017). Radiological diagnostic tools are therefore critical in achieving an accurate diagnosis in infants and younger children. Radiographs are the most commonly performed special investigation in children post trauma. These are typically performed in a special suite in the radiology department away from the relative safety of the trauma unit, where doctors, nursing staff and equipment are readily available. There are several disadvantages to this routine practice. Notwithstanding inevitable delays, the injured child requires conveyance to the radiology suite - a hazardous journey with numerous detrimental and fatal events having been reported (Mills, Raja \& Marin, 2016). It is therefore advantageous for an injured child to be imaged without removal from the clinical treatment area in the trauma unit that is designed and equipped to cope with all manner of clinical challenges.

Any medical procedure in a trauma unit can be intimidating and stressful for children (Blount et al., 2016). Resulting emotional upset should be kept to a minimum on humanitarian grounds and for the facilitation of physical and emotional healing. Infants and young children, when removed from their parents or familiar caregivers, generally become more distressed, which aggravates their pain and discomfort causing further anguish and diminished co-operation. Intimidating

\footnotetext{
${ }^{*}$ Corresponding author: sebastian.vanas@uct.ac.za

(C) 2019. The Author(s). Published under a Creative Commons CC-BY License.

http://Journals.uct.ac.za/index.php/GHI
} 
radiological equipment, machine noise, centering beams and low lighting within traditional radiology suites further increase patient anxiety. The imaging process is hence compromised by crying and patient movement, resulting in radiographs of sub-optimal technical quality (Rocha, Marche \& von Baeyer 2009; Kennedy, Luhmann \& Zempsky, 2008; American Academy of Paediatrics 2001). Paediatric patient positioning is particularly challenging in the absence of the caregivers when multiple radiographs are required in the instance of polytrauma screening (anteroposterior chest, lateral cervical spine, anteroposterior pelvis, skull and long bones) (Douglas et al., 2006). Unlike traditional radiography systems, the Lodox imaging system does not require patients to be removed from their caregivers for imaging purposes, as the scattered radiation produced by the system is very low. In addition, no repositioning of the patient is required, as a full body image is acquired rather than multiple images of a trauma screening series; this also reduces imaging time.

Various aspects of Lodox imaging in the paediatric age group have been reported in the scientific literature, particularly on the management of paediatric trauma (Pitcher et al. 2009; Douglas, Pitcher \& van As, 2010; Tummers, Isaacs \& van As 2013). Reports have also been published on the ease of scientific measurement of anatomical features in paediatric radiography (Sanders et al., 2009; Douglas et al., 2012). The application of the Lodox imaging system in paediatric practice at the Red Cross War Memorial Children's Hospital is currently expanding and new areas of anticipated clinical benefit are now being explored. These include skeletal surveys for screening non-accidental injury, skeletal surveys for metastatic or metabolic disease, mechanical axis evaluations for various orthopedic assessments such as limb length measurement, airway assessment for tuberculosis-related airway compression, investigation for aerodigestive foreign body ingestion or inhalation, and follow-up of response to bowel washouts in cases of chronic constipation or gut motility disorders, to name but a few.

Low-dose full-body radiography is an innovation that has been of immense benefit in paediatric trauma. It holds further promise for new applications that are being explored.

\section{References}

American Academy of Pediatrics 2001. The assessment and management of acute pain in infants, children, and adolescents. Paediatrics 108(3):793-7. Beningfield, S, Potgieter, H, Nicol, A, van As, S, Bowie, G, Hering, E \& Lätti, E 2003. Report on a new type of trauma full body digital X-ray machine. Emergency Radiology 10(1):23-9. DOI: 10.1007/s10140-003-0271-x

Blount, RL, Piira, T, Cohen, LL \& Cheng, PS 2006. Paediatric procedural pain. Behaviour Modification 30:2449. https://doi.org/10.1177/0145445505282438

Boffard, KD, Goosen, J, Plani, F, Degiannis, E \& Potgieter, H 2006. The use of low dosage X-ray (Lodox/Statscan) in major trauma: comparison between low dose X-ray and conventional x-ray techniques. Journal of Trauma 60(6):1175-81. DOI: 10.1097/01.ta.0000220393.26629.6c

Douglas, TS, Sanders V, Pitcher R, van As, AB.2008. Early detection of fractures with low dose digital X-ray images in a pediatric trauma unit. Journal of Trauma: Injury, Infection, and Critical Care 65: E4-E7. DOI: 10.1097/01.ta.0000198534.47134.bc

Douglas, TS, Pitcher, RD \& van As, AB 2010. Full body digital radiographic imaging of the injured child. Continuing Medical Education $28(3)$ : 108 112.

Douglas, TS, Gresak, LK, Koen, N, Fenton-Muir, N, van As, AB \& Pitcher, RD 2012. Measurement of prevertebral cervical soft tissue thickness on lateral digital radiographs. Journal of Paediatric Orthopaedics 32(3):249-252. DOI: 10.1097/BPO.0b013e31824b2811

Kennedy, RM, Luhmann, J \& Zempsky, WT 2008. Clinical implications of unmanaged needle-insertion pain and distress in children. Paediatrics 122 Suppl 3: S130-3. DOI: 10.1542/peds.2008-1055e

Knobel, GJ, Flash, G \& Bowie, GF 2006. Lodox Statscan proves to be invaluable in forensic medicine. South African Medical Journal 96(7):593-4.

Maas, AIR, Menon, DK, Adelson, PD et al 2017. Traumatic brain injury: integrated approaches to improve prevention, clinical care, and research. Lancet Neurology S11474-4422(17). DOI: 10.1016/S1474-4422(17)30371-X

Mills, EM, Raja, AS, Marin, JR 2015. Optimizing Diagnostic Imaging in the Emergency Department. Academic Emergency Medicine 22(5):625-31. DOI: 10.1111 acem. 12640

Mulligan, ME \& Flye, CW 2006. Initial experience with Lodox Statscan imaging system for detecting injuries of the pelvis and appendicular skeleton. Emergency Radiology 13(3):129-33. DOI: 10.1007/s10140-006-0525-5

Pitcher, RD, Wilde, JC, Douglas, TS \& van As, AB 2009. The use of the Statscan digital X-ray unit in paediatric polytrauma. Paediatric Radiology. 39(5):433-7. DOI: $10.1007 / \mathrm{s} 00247-008-1053-0$

Rocha, EM, Marche, TA \& von Baeyer, CL 2009. Anxiety influences children's memory for procedural pain. Pain Research Management 14:233-7.

Ron, E. 2002. Ionizing radiation and cancer risk: evidence from epidemiology. Pediatric Radiology 32: 232-237. DOI: 10.1007/s00247-002-0672-0

Sanders, VM, Pitcher, RD, Douglas, TS, Kibel, MA, Daya, RB \& van As, AB 2009. Digital radiographic measurement of the main bronchi: a pilot study. Annals of Tropical Paediatrics 29(3): 209-16.

Tummers, WS, Isaacs, S \& van As, AB 2013. Total body imaging evaluation after initial resuscitation in paediatric trauma. Injury Extra (44):37-8. http://dx.doi.org/10.1016/j.injury.2012.12.031

Willis, CE \& Slovis, TL 2004. The ALARA concept in pediatric CR and DR: dose reduction in pediatric radiographic exams: a white paper conference Executive Summary. Pediatric Radiology 35: S162-S164. DOI: 10.1007/s00247-004-1264-y

Zuidgeest, J, Jonkheijm, A, van Dijk, M \& van As, A 2013. Is the golden hour optimally used in South Africa for children presenting with polytrauma? South African Medical Journal 103(3):166-7. DOI: 10.7196/samj.6402 